\title{
CORRESPONDENCE
}

\section{Underreporting child abuse deaths: Experiences from a national study on child homicide}

To the Editor: Mortality is the most extreme consequence of child abuse, but it is not always conceptualised within the framework of child abuse and neglect. While undertaking research for the recent National Female and Child Homicide Study, it became apparent that medical practitioners, and especially forensic pathologists, often deviate from their legal and ethical obligations when the cause of a death raises suspicion of child abuse or neglect.

During data collection from mortuaries and police interviews, we encountered many instances where the Inquest $\mathrm{Act}^{[1]}$ and the Children's Amendment Act ${ }^{[2]}$ were not adhered to. Frequently, children's bodies had been released without a police investigation, particularly when death occurred in hospital. Whether it was assumed that a police case had been opened prior to the hospital admission, or whether the required involvement of the police had simply been forgotten, is unclear. In other cases where intentional injuries were suspected, attending doctors instructed families to open a police case. This abrogation of responsibility is not only in breach of the law, but is wholly inappropriate in child abuse and neglect, where parents or caregivers could be primary suspects.

In one case, an 8-month-old baby, who subsequently died of a subdural haematoma with a subarachnoid haemorrhage and cerebral oedema, was brought to a private hospital by the personnel of a crèche. Such injuries are highly indicative of non-accidental injury, and the mother was asked by the doctor to institute a police investigation. Unsurprisingly, an investigation could not be traced. Fatal child abuse remains hidden, and the perpetrators literally get away with murder. It is incumbent on forensic pathologists and medical practitioners who treat fatal injuries to ensure that suspicious cases are investigated.

The Inquest Act of 1959 instructs that all deaths which are deemed not to be due to natural causes undergo a postmortem examination to establish a cause of death, and a police investigation to establish whether someone can be held responsible for the death. ${ }^{[1]}$ Furthermore, Section 110(1) of the Children's Amendment Act of $2007^{[2]}$ mandates that such cases be reported to the police by all medical practitioners, 


\section{CORRESPONDENCE}

including the forensic pathologist who 'concludes on reasonable grounds' that a child's injury occurred in the context of abuse caused by physical injury, sexual abuse or deliberate neglect. A medical practitioner is not relieved of this duty with the death of a child, as this is the most extreme consequence of abuse. Such cases should receive additional attention. An investigation into the circumstances of the child's care and events leading to the child's death, in conjunction with postmortem findings, would assist in determining if someone can be held responsible for the death. We therefore strongly recommend that child abuse homicide case management and investigation receive as vigorous attention as any other case of suspected child abuse, since families may have other children who are similarly at risk.

There is an urgent need to strengthen reporting and management systems between Forensic Pathology Services (mortuaries) and the South African Police Service. South Africa needs to introduce multi-sectoral child death review (CDR) teams, so that all child injury deaths are reviewed, and factors amenable to intervention are identified, to prevent fatalities. In other countries, CDR teams have been shown to be effective in the identification of gaps in the child protection system, with the aim of preventing further child abuse fatalities. ${ }^{[3]}$ It is imperative that we promote the development of a CDR mechanism to increase protection for all children.

\section{Shanaaz Mathews}

The Children's Institute, University of Cape Town, and Gender \& Health Research Unit, South African Medical Research Council, Cape Town

shanaaz.mathews@uct.ac.za

\section{Naeemah Abrahams}

Rachel Jewkes

Gender \& Health Research Unit, South African Medical Research Council, Cape Town

\section{Lorna J Martin}

Division of Forensic Medicine and Toxicology, University of Cape Town

1. Inquest Act, 1959, Republic of South Africa. Pretoria: Government Gazette, 1959.

2. Children's Amendment Act 2007, No. 30884, Republic of South Africa. Pretoria: Government Gazette, 2008

3. Durfee M, Alexander R. Child fatality review teams. Pediatr Clin North Am 2009;56(2):379-387

S Afr Med J 2013;103(3):132-133. DOI:10.7196/SAMJ.6724 